\title{
Evaluating Nutrient Reduction, Grazing and Barley Straw as Measures Against Algal Growth
}

\author{
Veronica Fervier $^{1,2}$ (D) Pablo Urrutia-Cordero ${ }^{1,3,4,5} \cdot$ Elena Piano $^{2} \cdot$ Francesca Bona $^{2} \cdot$ Kenneth M. Persson ${ }^{6}$. \\ Lars-Anders Hansson ${ }^{1}$
}

Received: 25 November 2018 / Accepted: 26 April 2019

(C) Society of Wetland Scientists 2019

\begin{abstract}
The aim of our study was to experimentally investigate whether it is possible to reduce nuisance growth of filamentous algae in freshwater ecosystems. We used an experimental set-up mimicking a shallow pond system and performed a field investigation in the eutrophic moat of Krapperup castle (Southern Sweden), which exemplifies an extremely impaired ecosystem with ample growth of filamentous green algae. The indoor experiment tested three treatments: I) reduced nutrient concentrations, II) invertebrate grazers and III) addition of barley straw, which may constitute measures against filamentous algal growth and thereby improve the quality of the ecosystem services provided by water bodies. Our results show a decrease in cyanobacteria and diatom abundances in all mesocosms as filamentous algae biomass increased, suggesting that the microalgae suffered from nutrient and light competition with filamentous algae. A tendency for lower filamentous algae final biomass, as well as coverage, was observed in the treatment where the concentration of nutrients was reduced. Grazers treatment showed a tendency to inhibit filamentous algae growth on artificial macrophytes towards the end of the experiment, suggesting that snails initially fed on their preferred food source (diatoms), until it was almost depleted and then started to feed on filamentous algae. Interestingly, the barley straw treatment was the only treatment promoting macrophytes growth and enhancing diatom biomass, but this did not affect filamentous algae biomass. However, the ratio between filamentous algae and macrophyte final biomasses was significantly lower in the straw treatment. In a broader context, it is likely that in a long-term perspective the positive effect of barley straw on macrophyte growth will promote a shift from dominance by filamentous algae to macrophytes as main primary producer. Moreover, our experiment shows that barley straw may be effective in reducing cyanobacterial growth, which may lead to improved water quality and thereby ecosystem services, such as supporting and cultural ecosystem services, since cyanobacteria may produce potent toxins and pose a serious risk to human and animal health. Altogether, our experimental results have important implications for the challenge of reversing nuisance filamentous algal blooms in highly eutrophic systems.
\end{abstract}

Keywords Filamentous algae $\cdot$ Eutrophication $\cdot$ Freshwater $\cdot$ Ponds $\cdot$ Mesocosms $\cdot$ Restoration $\cdot$ Cyanobacteria

Electronic supplementary material The online version of this article (https://doi.org/10.1007/s13157-019-01167-6) contains supplementary material, which is available to authorized users.

Veronica Fervier

Pablo Urrutia-Cordero

pablo.urrutiacordero@ebc.uu.se

Elena Piano

elena.piano@unito.it

Francesca Bona

francesca.bona@unito.it

Kenneth M. Persson

kenneth_m.persson@tvrl.Ith.se

Lars-Anders Hansson

lars-anders.hansson@biol.lu.se
1 Department of Biology/Aquatic Ecology, Lund University, Sölvegatan, 3722362 Lund, Sweden

2 Department of Life Sciences and Systems Biology, University of Turin, Via Accademia Albertina 13, I-10123 Turin, Italy

3 Department of Ecology and Genetics/Limnology, Uppsala University, Norbyvägen 18D, Uppsala, Sweden

4 Helmholtz Institute for Functional Marine Biodiversity (HIFMB), Ammerländer Heerstraße 231, 26129 Oldenburg, Germany

5 Institute for Chemistry and Biology of Marine Environments (ICBM), Carl-von-Ossietzky University Oldenburg, Schleusenstrasse 1, 26382 Wilhelmshaven, Germany

6 Division of Water Resources Engineering, Lund University, John EricssonsVäg 1, V-Hus, Lund, Sweden 


\section{Introduction}

Clean water is a crucial resource for drinking, irrigation, industry, transportation, recreation, fishing, hunting, support of biodiversity, and also for aesthetic reasons (Carpenter et al. 1998). Therefore, scientists and policy-makers have widely come to accept that natural resources need to be protected from the destructive actions of human activities, since people inevitably harm natural resources as they use them. Moreover, the human population size is increasing globally, which translates into more pronounced impact on water, land and atmospheric resources (Pretty et al. 2003). In fact, in the past decades, large volumes of urban, agricultural and industrial wastewater have been produced, which have greatly increased the input of nutrients, such as nitrogen and phosphorus, as well as other pollutants into natural water bodies (Xin et al. 2010; Boelee et al. 2011; Abdel-Raouf et al. 2012).

Eutrophication is a leading cause of impairment of many freshwater and coastal marine ecosystems in the world (Chislock et al. 2013). This phenomenon is characterized by excessive plant and algal growth due to the increased availability of one or more limiting growth factors needed for photosynthesis, such as phosphorus or nitrogen (Schindler 2006). Therefore, a relevant question is whether there are possibilities to reverse such effects by making ecologically sustainable changes. For example, many waters exposed to eutrophication are overgrown with filamentous macroalgae covering macrophytes and leading to reduced quality of ecosystem services (Phillips et al. 1978, 2016). In order to address the question if such nuisance growth can be counteracted, we conducted an experiment to test three ecologically sustainable solutions to reduce algae growth and determine whether these can be used to restore degraded ecosystems. Our indoor mesocosm experiment experimentally tested the effects of (1) nutrient reductions, (2) grazing pressure and (3) chemical interference through barley straw.

The main cause of algal accumulations is a surplus of nutrients, particularly phosphorus and nitrogen in the water column (Søndergaard 2007; Nelson et al. 2013). Since primary production is strongly limited by nutrient availability, they play a decisive role for the environmental state of water bodies (Søndergaard 2007). Particularly phosphorus and nitrogen are important among the many nutrients that, apart from carbon, contribute to plant primary production and, thus form the basis for the other components of the food chain. This is because phosphorus and nitrogen often function as limiting nutrients and thereby determine phytoplankton abundances (Dillon and Rigler 1974; Moss 2001; Maberly et al. 2003). Nitrogen typically occurs in concentrations much higher than those of phosphorus and, despite that the demand by primary producers for nitrogen is higher than for phosphorus, there will often be a nitrogen surplus (Søndergaard 2007). Moreover, available nitrogen may, contrary to phosphorus, be formed in the lakes via cyanobacterial fixation of $\mathrm{N}_{2}$, although several investigations indicate that this normally constitutes only a minor fraction of the total nitrogen supply (Jeppesen 1998; Ferber et al. 2004). We applied treatment reduction with respect to both nitrogen and phosphorus to test if it was sufficient to reduce algae growth.

In addition to nutrients, snails are also an important as herbivores in many freshwater systems, and several experimental studies have shown that snail grazing has strong effects on epiphytic algal biomass, species composition, architecture, and productivity (Brönmark 1989; Stevenson et al. 1996). Freshwater pulmonate snails are commonly found in association with macrophyte vegetation and their epiphyton (Underwood et al. 1992). These macrophytes provide sites for snail oviposition, access to the air-water interface and shelter, as well as providing a surface for periphytic algal development, which constitutes a major source of food for freshwater snails (Underwood et al. 1992). Filamentous green algae are one of the most noted nuisance periphyton group (Biggs and Price 1987; Welch et al. 1989, 1992). The removal of periphyton by grazing invertebrates is well documented (Lamberti and Moore 1984; Colletti et al. 1987; Jacoby 1987; Steinman et al. 1987a, b; Power et al. 1988; Feminella and Hawkins 1995), even if earlier studies (Gregory 1983) emphasized grazer preference for diatoms and avoidance of the larger filamentous green algae.

Aerobic decomposition of barley straw has been shown to inhibit growth of filamentous algae under both laboratory and field conditions (Ridge and Pillinger 1996; Caffrey and Monahan 1999; Martin and Ridge 1999; Barrett et al. 1999; Ball et al. 2001; Geiger et al. 2005; Houman Rajabi Islami and Filizadeh 2011). A primary requirement for the successful use of barley straw is the maintenance of aerobic conditions (Ridge and Pillinger 1996). According to literature, unstable, shortlived algal inhibitors are released during aerobic decomposition of the straw and these are highly selective against planktonic and filamentous algae (Newman and Barrett 1993). There is strong evidence that these algal inhibitors are derived from oxidized polyphenolics released from solubilized lignin (Ridge and Pillinger 1996), although the precise nature of the inhibitors or their mode of action remains unknown. The effects of more than 100 barley straw treatments in the U.K. and Ireland were documented by Newman and Barrett (1993) and results revealed that algal control was achieved, at least to some extent, in all types of water bodies, but was most pronounced in smaller ponds ( $<5 \mathrm{ha})$. Barley straw is now in widespread use as a method for controlling algal growth, since it is inexpensive and shows no adverse ecological effects (Geiger et al. 2005). However, some studies have shown a weak or even absent inhibitory effect on algae (Boylan and Morris 2003; Prygiel et al. 2014). Furthermore, some studies suggest that barley straw should be placed in the water body several months before bloom conditions are expected (Geiger et al. 2005). 
The overall aim of this study was to test which of these three commonly used measures is most efficient and to provide recommendations on how to handle nuisance algal growth at the local scale. Hence, our experiment was run in connection to the real case at Krapperup castle moat (Scania, Southern Sweden), which exemplifies an impaired ecosystem with high nutrient concentrations (phosphorous and nitrogen) and which exhibits consistent filamentous algae blooms from spring to autumn.

\section{Material and Methods}

\section{The Krapperup Case Study}

Krapperup is a castle in Höganäs municipality, Scania, in southern Sweden (56 $56^{\circ} 15^{\prime} 26.01^{\prime \prime} \mathrm{N} ; 12^{\circ} 31$ ' 28.83” E), representing a well-connected environment with a castle, a park and modern farming. The total area of 2750 ha includes farmhouses, pastures and forests (http://krapperup.se). In September 2016 we performed a survey of the Krapperup moat, which is characterized by shallow waters with an average depth of $0.46 \mathrm{~m}$. The moat is $4074 \mathrm{~m}^{2}$ and contains $2851 \mathrm{~m}^{3}$ water. The average turbidity was 7.3 NTU, i.e. the water was clear and light easily penetrated to the bottom. The average $\mathrm{pH}$ in the moat was 7.8. Total nutrient concentrations measured in the waters of the moat were very high with an average total phosphorous concentration of $213 \mu \mathrm{gL}^{-1}$ and an average total nitrogen concentration of $1450 \mu \mathrm{gL}^{-1}$. After measuring the depth of the moat and the coverage (COV) of macrophytes and filamentous algae, in percentage of the total observed area, we calculated the proportion mean PVI (\%) (plant volume infested) in each sampling point as:

$\mathrm{PVI}=\frac{\mathrm{COV} * \text { mean plant height }}{\text { water depht }} * 100$

Macrophytes in the moat belong to the genus Potamogeton, with only 6\% PVI. The average PVI of the filamentous algae was $32.5 \%$, with highest values in the East- and South-facing sides of the moat, where it reached PVI 90\%. Samples for chlorophyll-a concentration ( $\mu \mathrm{g}$ chl$\mathrm{aL}^{-1}$ ) analysis were taken from each side of the moat and analysed to evaluate the concentration of cyanobacteria and diatoms. The average concentration of cyanobacteria was $4.08 \mu \mathrm{g}$ chl-a $\mathrm{L}^{-1}$ and the average diatom concentration was $9.26 \mu \mathrm{g}$ chl-aL ${ }^{-1}$.

In November 2016, we collected material for the indoor mesocosm experiment from the Krapperup moat: $150 \mathrm{~L}$ of unfiltered water, $100 \mathrm{~L}$ of sediment and macrophytes (Potamogeton pectinatus). The experiment consisted of 28 aquaria, in which 4 treatments (with 7 replicates each) were tested: control, grazers, nutrient reduction and barley straw.
The water was collected in polyethylene jerry cans. The sediment was collected by using hand nets and placed in dark polyethylene boxes. Macrophytes were harvested manually from the moat and placed in a dark bucket with moat water. All the material collected was transported to the experimental facilities within 4 hours of sampling.

\section{Experimental Set up and Maintenance}

The experiment was run for 80 days, from November 2016 to January 2017 , in the greenhouse of Lund University $\left(55^{\circ} 42^{\prime}\right.$ $\mathrm{N} 13^{\circ} 12^{\prime}$ E). The experimental mesocosms consisted of 28 transparent polypropylene aquaria $(39 \times 28 \times 28 \mathrm{~cm})$ with a capacity of $22 \mathrm{~L}$. To initiate the experiment, we placed $3 \mathrm{~cm}$ of previously homogenized moat sediment at the bottom of each aquarium and then filled each of them with $10 \mathrm{~L}$ of unfiltered water collected from the moat and tap water in different proportions depending on the treatment. We did not filter neither the sediment nor the water, ensuring a certain number of grazers in each treatment, thereby mimicking natural conditions. The tap water used did not contain any nitrogen or phosphorous, since they are removed in the slow sand filters at the Ringsjöverket, the drinking water treatment plant that supplies drinking water to Lund (Lidén 2016).

Each experimental treatment had 7 replicates and each aquarium was filled with $6 \mathrm{~L}$ of unfiltered water from the Krapperup moat and $4 \mathrm{~L}$ of tap water, except for the nutrient reduction treatment in which we added $2 \mathrm{~L}$ instead of $6 \mathrm{~L}$ of unfiltered water from the moat and $8 \mathrm{~L}$ of tap water, thereby reducing the nutrient concentration in the water column.

In the grazing treatment we added 25 Lymnea stagnalis snails to each aquarium. Snails were taken both from the moat and from an aquaria culture at Lund University. Lymnaea stagnalis is known to be a grazer on filamentous algae (Brönmark et al. 1991), although other studies have shown that snails prefer diatoms (Calow and Calow 1975; Skoog 1978). In any case, growth and reproduction of L. stagnalis can be sustained on a diet based on filamentous algae, but growth rate is higher when fed with more high-ranked food items (Skoog 1978). We applied this treatment (presence of snails) to test if a high presence of grazers can limit the growth of filamentous algae on macrophytes and thus improve the health status of macrophytes, triggering a shift to a state with macrophytes as dominant primary producers.

In the barley straw treatment we put $10 \mathrm{~g}$ of fresh barley straw (packed in a plastic net) in each aquarium and also added $35 \mathrm{~mL}$ of barley straw extract. The extract was prepared by cutting $10 \mathrm{~g}$ of fresh barley straw into uniform lengths $(2 \mathrm{~cm})$ which were then boiled in $250 \mathrm{ml}$ of tap water according to Ball et al. (2001). After cooling, the solution was filtered through a glass fibre filter. We tested a combination of fresh straw and straw extract, in order to prevent fresh barley straw delayed decay from masking the effect of straw-derived 
algistatic components. The control aquaria were identical to all other treatments except that they did not receive any experimental manipulation.

In each aquarium, we planted $2.5 \mathrm{~g}$ (wet weight) of Potamogeton pectinatus collected from the moat and $2.5 \mathrm{~g}$ of Myriophyllum spicatum (wet weight) collected in a stream near the greenhouse of Lund University where the experiment was conducted. We added Myriophyllum spicatum, even if it is not a species naturally present in the moat, because Potamogeton is known to be rapidly out-competed by other species (Birkinshaw et al. 2013). In the experiment, we also aimed to test the effect of filamentous algae on macrophytes and vice versa. For this reason, we needed a macrophyte species that was more likely to survive for the entire experimental period. Myriophyllum spicatum occurs in various sediment types and can tolerate low-light environments, such as highly eutrophic waters (Smith and Barko 1990), and is therefore widely used for eutrophic lake restoration (Gao et al. 2007). We also added artificial plastic macrophytes ( 9 branches) to each aquarium in order to estimate filamentous algae growth on standardized surface areas with macrophyte-like morphology. At the beginning of the experiment the weight and coverage of filamentous algae on artificial macrophytes was zero.

The aquaria were kept at $81 \mu \mathrm{mol} \mathrm{m}{ }^{-2} \mathrm{~s}^{-1}$ at a $14-10 \mathrm{~h}$ light-dark cycle and the water temperature in the aquaria ranged between 14.5 and $16.5^{\circ} \mathrm{C}$ during the experiment. Distilled water was added weekly to compensate for evaporation losses. The aquaria were open and exposed to air.

\section{Sample Collection and Analysis}

Temperature, dissolved oxygen (using OxyGuard Handy Oxygen Meter) and $\mathrm{pH}$ using a pH meter (EUtech Scientific Engineering $\mathrm{GmbH}$, Aachen, Germany) were measured every 10 days. The oxygen saturation trend measured was similar for all the treatments and ranged between $100 \%$ and $145 \%$. Similarly, the $\mathrm{pH}$ trend measured was similar for all the treatments and ranged between $\mathrm{pH} 8.3$ and $\mathrm{pH}$ 9.6.

Filamentous algae coverage on the surface of the water was visually estimated for each aquarium every 20 days (in total four sampling occasions) and we considered it to be zero at the beginning of the experiment. Similarly, filamentous algae growth on artificial macrophytes was measured every 20 days (in total four sampling occasions), cutting one branch of the artificial macrophyte in each aquarium and then scrubbing off attached filamentous algae. Finally, we weighed the branch and the filamentous algae growing on it (dry weight). For each sampling occasion, with the following formula, we calculated the percentage of filamentous algaegrown on artificial macrophytes.

$x=\frac{\text { Filamentous algae weight }}{\text { artificial macrophyte branch weight }+ \text { Cladophora weight }} * 100$
Chlorophyll-a analyses were performed to assess the effect of different treatments and of filamentous algae growth on the phytoplankton community, particularly on cyanobacteria in view of their possible toxicity and diatoms, since the latter are nutritious food for many grazers. Samples for assessment of chlorophyll-a concentration ( $\mu \mathrm{g}$ chl-a $\mathrm{L}^{-1}$ ) were taken from each aquarium every 20 days (in total four sampling occasions) through a polyethylene bottle with a filter ( $50 \mu \mathrm{m}$ mesh size) in order to avoid contamination by filamentous algae filaments, i.e. only phytoplankton were sampled. Chlorophyll was analysed with a fluorometer (AlgaeLabAnalyser, ALA, bbe moldaenke, Germany), within 1 hour of sampling.

At the end of the experiment all macrophytes and filamentous algae were taken out of each aquarium, dried and weighted. The above and belowground part of the macrophytes were weighted separately.

\section{Data Analyses}

Two-way repeated measures Analysis of Variance (RMANOVA), with incubation time and the experimental treatments as factors, was used to analyse treatment and incubation time effects on filamentous algae coverage on the surface, on filamentous algae growth on artificial macrophytes, as well as on diatom and cyanobacteria biomass expressed as $\mu \mathrm{g}$ chl-a $\mathrm{L}^{-1}$. Data were log-transformed before statistical analyses to achieve a normal distribution. Pairwise differences between treatments were checked with the Tukey's post-hoc test. Kruskal-Wallis test was used to evaluate the treatment effect on total filamentous algae and macrophyte biomass in each aquarium at the end of the experiment, as well as on the ratio between the final biomass of filamentous algaeand that of the macrophytes. RM-ANOVA, Tukey's post-hoc test and graphs were performed with R (R Development Core Team 2015), while the Kruskal-Wallis test was performed in StatXact v5 (C) Cytel Software, 2001).

\section{Results}

\section{Filamentous Algae Growth}

The coverage of filamentous algae increased significantly in all treatments (Table 1) and we recorded significant differences at sampling occasions 1,2 and 3 (Fig. 1a; RMANOVA: $\mathrm{F}_{3,101}=86.3$; Tukey's post-hoc: $p$ value $<0.001$ ). The coverage was significantly lower in the reduced nutrient treatment compared to the control (Fig. 1a; RM-ANOVA: $\mathrm{F}_{3,101}=2.76$ Tukey's post-hoc: $\mathrm{p}$ value $=0.032$ ). There were no significant differences among the other treatments, although there was a tendency for a lower filamentous algae coverage in the snail treatment (Fig. 1a). 
Table 1 Results of the RMANOVA. For both factors tested (Treatment and incubation time) the $\mathrm{F}$ and $p$ values are reported

\begin{tabular}{lll}
\hline & Treatment & Incubation time \\
\hline Filamentous algae coverage & $F 3,101=2.76 ; p=0.046$ & $F 3,101=86.3 ; p<0.001$ \\
Filamentous algae weight & $F 3,101=1.64 ; p=0.186$ & $F 3,101=25.8 ; p<0.001$ \\
Diatom (chl-a) & $F 3,101=10.3 ; p<0.001$ & $F 3,101=30.8 ; p<0.001$ \\
Cyanobacteria (chl-a) & $F 3,101=6.62 ; p<0.001$ & $F 3,101=29.0 ; p<0.001$ \\
\hline
\end{tabular}

Filamentous algae growth on artificial macrophytes (Fig. 1b) was significantly affected by the incubation time but not by the treatment (Table 1). Although growth on artificial macrophytes increased in all treatments, the growth lagged behind the filamentous coverage at the surface, and showed no differences between sampling occasions 1 and 2, while growth increased significantly between sampling occasions 2 and 3 (Fig. 1b; RM-ANOVA: $\mathrm{F}_{3}, 101=25.8$; Tukey's post-hoc: $p$ value $<0.001)$. There were not significant differences between treatments, although there were tendencies for a lower growth in the nutrient treatment (Fig. 1b). The barley straw treatment initially inhibited filamentous algae growth on artificial macrophytes, but the effect disappeared after about 50 days of incubation (Fig. 1b). The grazer treatment showed no initial effect on filamentous algae growth on artificial macrophytes, although there was a tendency for reduced filamentous algae biomass at the end of the experiment (Fig.1b).

Hence, the final filamentous algae biomass increased in all treatments overtime, but did not differ significantly among treatments, although there was a tendency for lower biomass in the reduced nutrient treatment (Fig. 2d; Table 2).

\section{Phytoplankton Community Responses}

Cyanobacteria concentration ( $\mu \mathrm{g}$ chl-aL $\left.{ }^{-1}\right)$ was significantly affected by both the incubation time and treatment (Fig. 1c; Table 1), and showed an inverse hump-shaped response since it initially significantly decreased in all treatments between sampling occasions 1 and 2 (Fig. 1c; RM-ANOVA: $\mathrm{F}_{3,101}=29.0$; Tukey's post-hoc: $p$ value $<0.001)$. However, the concentration of cyanobacteria ( $\mu \mathrm{g}$ chl-a $\mathrm{L}^{-1}$ ) showed a significant increase in all treatments, including the control, towards the end of the experiment. The cyanobacteria concentration $\left(\mu \mathrm{g} \mathrm{chl-a} \mathrm{L}^{-1}\right)$ was significantly lower in the barley straw treatment compared to all the other treatments and the control (Fig. 1c; RMANOVA: $\mathrm{F}_{3,101}=6.62$ Tukey's post-hoc: $p$ value $=0.014$ ). Barley straw inhibited cyanobacterial growth, but this
Fig. 1 The effects of treatment and incubation time. Boxplots showing first quartile, median and third quartile values observed for (a) Filamentous algae coverage (\%), (b) Filamentous algae growth on artificial macrophytes (g), (c) Diatom chlorophyll-a concentration $\left(\mu \mathrm{g} \mathrm{L}^{-1}\right)$ and (d) Cyanobacteria chlorophyll-a concentration $\left(\mu \mathrm{g} \mathrm{L}^{-1}\right)$. Dots represent outliers
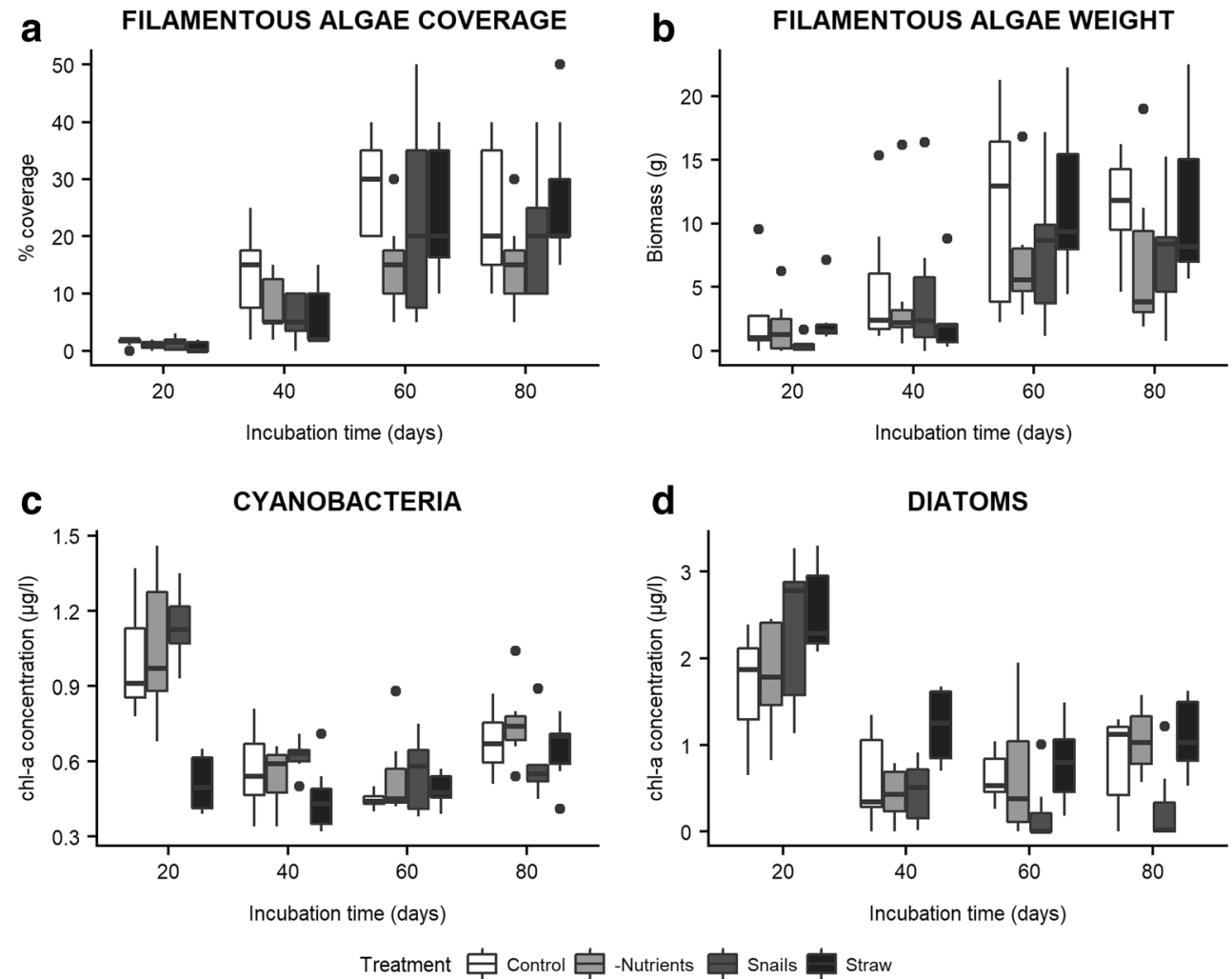

d

DIATOMS

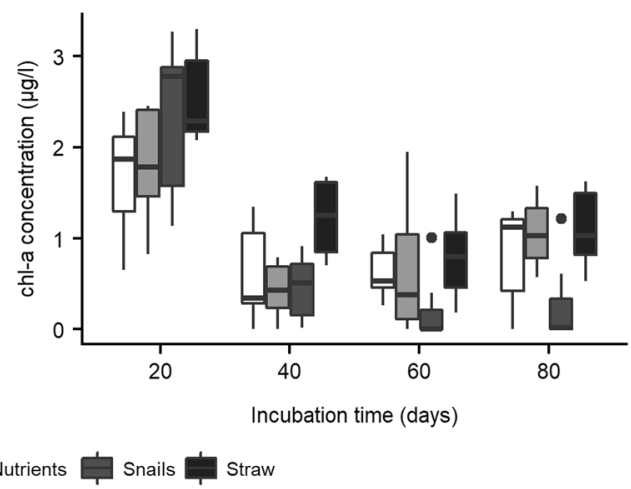


Fig. 2 The effects of treatments at the end of the experiment. Boxplots showing first quartile, median and third quartile values observed for (a) total macrophyte final biomass $(\mathrm{g}),(\mathbf{b})$ aboveground macrophyte final biomass (g), (c) belowground macrophyte final biomass $(\mathrm{g})$ and (d) total filamentous algae final biomass (g). Dots represent outliers

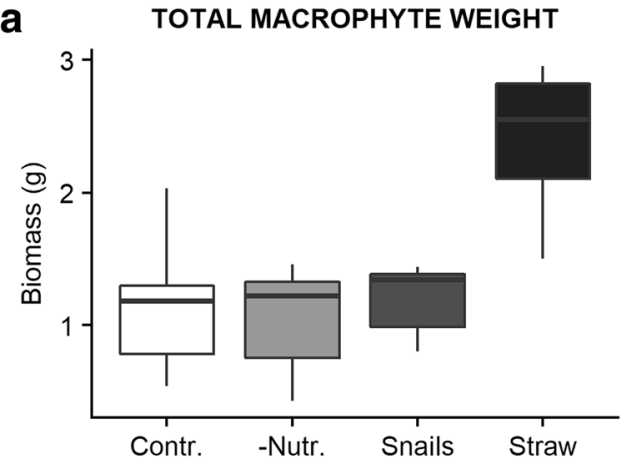

b MACROPHYTE ABOVE GROUND WEIGHT

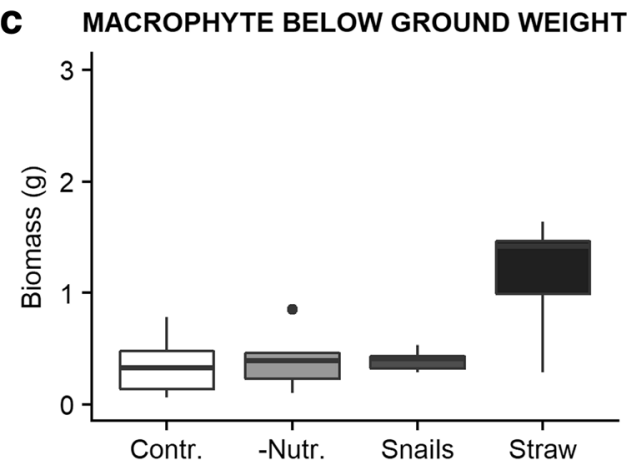

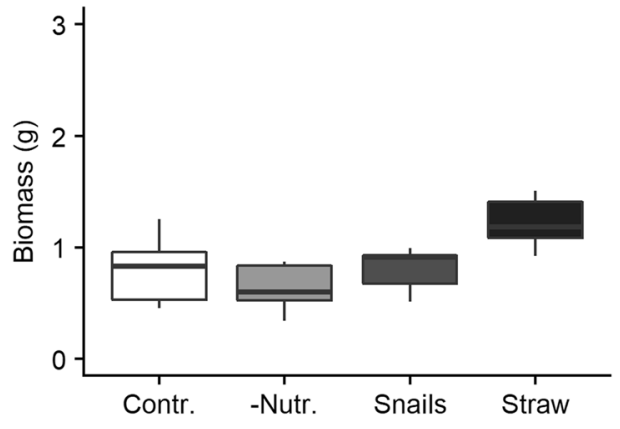

FILAMENTOUS ALGAE WEIGHT

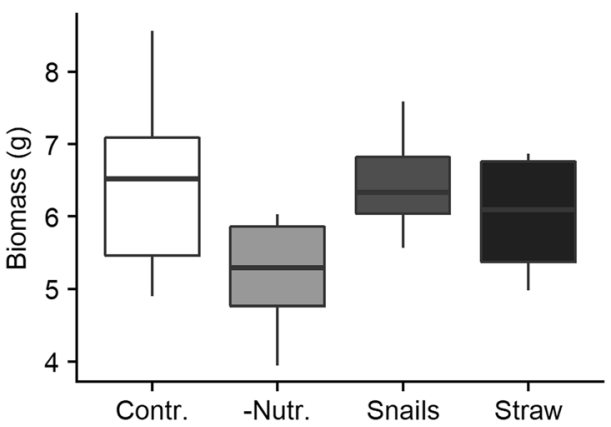

seemed to be a short-term effect, since cyanobacteria concentration increased again towards the end of the experiment (Fig. 1c).

The diatom concentration ( $\mu \mathrm{g}$ chl-a $\mathrm{L}^{-1}$ ) was significantly affected by both the incubation time and the treatment (Fig. 1d; Table 1). It initially decreased in all treatments (Fig. 1d; RM-ANOVA: $\mathrm{F}_{3,101}=30.8$; Tukey's post-hoc: $p$ value $<0.001$ ), whereas the following sampling occasions ( 3 and 4) did not show any significant differences in diatoms concentration. However, the diatom concentration was significantly higher in the barley straw treatment compared to all other treatments and the control (Fig. 1d; RM-ANOVA: $\mathrm{F}_{3,101}=$ 10.3; Tukey's post-hoc: $p$ value $<0.031$ ). From our results it appears that there is a tendency for a lower concentration of diatoms in the treatment with snails, starting from the sixtieth day of incubation (Fig. 1d).

Table 2 Results of the Kruskal-Wallis test on the final biomass of filamentous algae, as well as total, above- and below-ground macrophyte biomasses. For each variable, the $\mathrm{W}$ and $\mathrm{p}$ values are reported

Total filamentous algae biomass

Total macrophytes biomass

Below-ground macrophytes biomass

Above-ground macrophytes biomass

Ratio between filamentous algae

and macrophyte biomass

$$
\begin{aligned}
& W=6.090 ; p=0.1007 \\
& W=12.72 ; p=0.0021 \\
& W=7.031 ; p=0.0584 \\
& W=14.08 ; p=0.0015 \\
& W=10.79 ; p=0.002
\end{aligned}
$$

\section{Macrophytes Response}

Macrophyte final biomass showed significant differences between treatments and the control (Fig. 2a; Table 2). In particular, total macrophyte biomass was significantly higher in the straw treatment compared to the other treatments and the control (Fig. 2a; Kruskal-Wallis: $\mathrm{W}=12.72$; $\mathrm{p}$ value $=0.0021$ ). These differences were significant with regard to the aboveground part of macrophytes, whose biomass was significantly higher in the straw treatment (Fig. 2b; Kruskal-Wallis: W = $14.08 ; \mathrm{p}$ value $=0.0015$ ). There were no significant differences at the 5\% level in the belowground macrophyte biomass, although there was a tendency for higher biomasses in the straw treatment (Fig. 2c).

\section{Ratio Between Final Filamentous Algae and Macrophytes Biomass}

Significant differences among treatments were observed for the ratio between the final biomasses of filamentous algae and macrophytes (Fig. 3; Kruskal-Wallis: $\mathrm{W}=10.79$; $\mathrm{p}$ value $=$ 0.002 ), with lower values, i.e. stronger dominance of macrophytes, in the straw treatment compared to the other treatments.

\section{Discussion}

Our experimental results show that filamentous algae coverage started to increase substantially in all treatments from the 
FILAMENTOUS ALGAE/MACROPHYTES RATIO

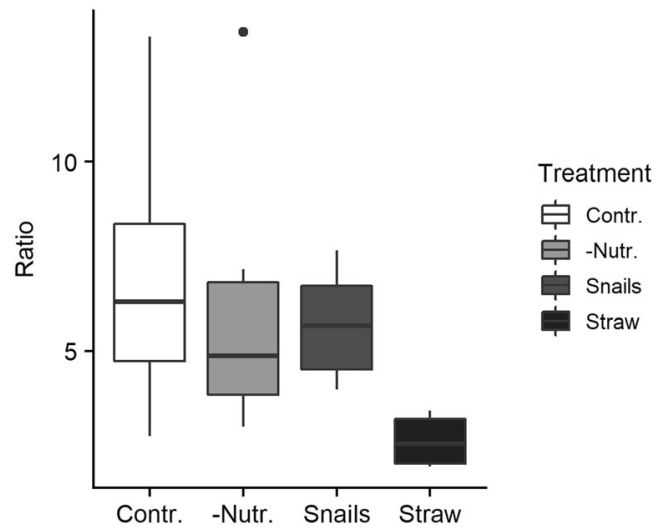

Fig. 3 Boxplots showing final filamentous algae and macrophyte weight ratio in response to the different treatments. Dots represent outliers

beginning of the experiment and then declined after reaching a peak. Under nutrient limitation there was significantly lower coverage, a notion strengthened by a tendency in terms of filamentous algae growth also on artificial plants. None of the treatments used in the experiment resulted in a significant decline in filamentous algae final biomass. However, in the barley straw treatment we found an increase in macrophyte growth, which resulted in a lower filamentous algae/macrophyte ratio, suggesting less filamentous algae filaments per macrophyte. There was a decrease in cyanobacteria and diatom concentrations in all aquaria as filamentous algae biomass increased, suggesting that the microalgae suffered from nutrient and light competition with filamentous algae, which progressively covered the water surface (Cheney and Hough 1983).

Although removal of periphytic algae by grazing invertebrates is well documented (Lamberti and Moore 1984; Jacoby 1987; Steinman et al. 1987a, b; Power et al. 1988; Feminella and Hawkins 1995), earlier studies (Gregory 1983) have emphasized a grazer preference for diatoms and avoidance of the larger filamentous algae. Our results confirmed a clear preference of Lymneid snails for diatoms, as diatoms declined after 60 days of grazer treatment, whereas filamentous algae was a non-preferred food item (Calow and Calow 1975; Skoog 1978). However, in our experiment the snail treatment showed a tendency to inhibit filamentous algae growth on artificial macrophytes towards the end of the experiment. This result goes hand in hand with diatom inhibition, in fact towards the end of the experiment the snail treatment was the one with the lowest diatom concentration. It is conceivable that snails initially fed on their preferred food source (diatoms), until it was almost depleted and towards the end of the experiment, when diatom concentration was approaching zero, snails were likely forced to feed on filamentous algae.

In previous studies, barley straw has been shown to inhibit a wide range of algae, comprising both filamentous types (Welch et al. 1990) and phytoplankton (Gibson et al. 1990) including cyanobacteria (Newman and Barrett 1993). The anti-algal activity of barley straw has yet to be elucidated, although several authors suggest that phenolic compounds derived from lignin play a role in the inhibition of algae (Ridge and Pillinger 1996). Our results confirmed these previous studies, showing that filamentous algae coverage on the water surface and on artificial macrophytes declined in the barley straw treatment, although this effect disappeared after about 50 days of incubation. Moreover, our results show that barley straw may be effective in reducing cyanobacterial growth, but even this turned out to be a short-term effect, since cyanobacteria concentration increased again towards the end of the experiment. Hence, barley straw treatment had, for all the components examined, a short-term effect. Our results also show that barley straw promoted diatom growth, since the diatom concentration was significantly higher in the barley straw treatment. As suggested by Ridge and Pillinger (1996), diatoms seem to be resistant to barley straw effects and in our study they seem to be further favoured by the decline in cyanobacteria in the barley straw treatment. Moreover, Caffrey and Monahan (1999) demonstrated that after barley straw treatment, water transparency improved and Myriophyllum spicatum and Elodea canadensis showed increased growth. Our results are in line with those showing that barley straw treatment was the only treatment promoting macrophyte growth. Previous studies (Welch et al. 1990; Newman and Barrett 1993; Everall and Lees 1996; Caffrey and Monahan 1999), have observed that macrophyte growth is enhanced by barley straw, following a reduction in algal biomass. Here, we demonstrate that the primary mechanism behind the effects of barley straw is the promotion of macrophytes growth, which in our experiment occurred without any noticeable effect on the filamentous algae biomass, and led to that the ratio between filaments and macrophytes declined. A likely explanation of these results may be that macrophytes are stimulated by barley straw and that higher macrophyte biomass competes with the algae for nutrients and light, thus leading to a secondary effect on algae. Hence, our study adds to previous knowledge by identifying that the main effect of barley straw is an improvement in the growth of macrophytes which in the long run may have an indirect effect on the biomass of filamentous algae.

Widespread problems as a result of eutrophication of shallow lakes has invoked numerous restoration projects in the last decades, in which even after a considerable reduction in the external loading of nutrients have often not led to desired recovery to the original state of the water bodies (Phillips et al. 1978; Meijer et al. 1989; Scheffer and Van Nes 2007). One of the most influential idea that emerged from research into the causes of this hysteresis is the theory that such lakes can be in two alternative stable states: a clear state with abundant submerged macrophytes in which invasion by filamentous algae is prevented by reduced nutrient availability or a turbid state 
where algae dominate with few submerged plants whose growth is prevented by shading (Hutchinson 1975; Spence 1982; Timm and Moss 1984; Hosper 1989; Chambers et al. 1989; Ozimek et al. 1990; Jeppesen et al. 1991; Scheffer et al. 1993; Scheffer 1998; Scheffer and Van Nes 2007). The shift to floating plant dominance is difficult to reverse and can happen when a critical threshold level of nutrients is passed. This bistability often makes reversal of filamentous algae invasion of a lake difficult (Scheffer and Van Nes 2007).

In accordance with the alternative stable state theory (Scheffer et al. 1993; Scheffer and Van Nes 2007), barley straw treatment may then be a tool to shift a system from algal to macrophyte dominance as primary producers. Our study clearly identifies a strong positive response of submerged macrophytes to barley straw treatment, suggesting that the compounds released by barley may not primarily be affecting nuisance algal growth, such as filamentous algae and cyanobacteria, but rather stimulate their macrophyte competitors. This notion is strengthened by our analysis of the filamentous algae / macrophyte ratio, which highlights a significantly lower amount of filaments per macrophytes in the barley straw treatment. Our results also suggest that competition between macrophytes and filamentous algae for light is important, demonstrated by the increase in above ground biomass, compared to the below ground biomass of macrophytes. Hence, macrophytes may invest in their aboveground development rather than in the root system to reach the surface of the water and there by avoid the negative influence of shading from filamentous algae. A deeper understanding of barley straw bio-stimulation effects on macrophytes would be useful and in a broader context, barley straw treatments of eutrophic waters may be a valid management option to promote a shift from dominance by filamentous algae to macrophytes as main primary producers.

Altogether, our experimental results have important implications for the challenge of reversing nuisance algal blooms in highly eutrophic systems. Although conclusions derived from experimental studies have to be interpreted with caution, they provide a useful intermediate scale between short-term laboratory studies and whole lake manipulations, especially by mimicking water bodies structurally similar and by enabling replication (Urrutia-Cordero et al. 2017). In conclusion, we show that nutrient reduction is the only treatment that manifested any tendency to reduce the biomass of filamentous algae. However, barley straw treatment resulted in a considerable increase in macrophyte growth, therefore the amount of filamentous algae per macrophyte declined, suggesting reduced competition from filamentous algae. Hence, although we found no direct effect of barley straw treatment on filamentous algal growth, barley straw may alter the dominance pattern between filamentous algae and macrophytes and thereby improve the quality of the ecosystem services provided by water bodies.
Acknowledgements This research was funded by The Royal Physiographic Society and the Sweden Water Research. The greenhouse and laboratories were made available by Department of Biology, Lund University.

Authors' Contributions VF, together with PUC and LAH conceived, planned, carried out the experiment, performed the samplings and wrote the manuscript. PUC performed the samplings in the study area in September 2016. EP performed the statistical data analysis. KMP and FB supervised the project. LAH was involved in planning, provided critical feedback, helped shape the research and was the main supervisor of the work. All authors discussed the results and contributed to the final manuscript.

\section{References}

Abdel-Raouf N, Al-Homaidan A, Ibraheem I (2012) Microalgae and wastewater treatment. Saudi Journal of Biological Sciences 19(3): 257-275

Ball AS, Williams M, Vincent D, Robinson J (2001) Algal growth control by a barley straw extract. Bioresource Technology 77:177-181

Barrett PRF, Littlejohn JW, Curnow J (1999) Long-term algal control in a reservoir using barley straw. Hydrobiologia 415:309-313

Biggs BJ, Price GM (1987) A survey of filamentous algal proliferations in New Zealand Rivers. New Zealand Journal of Marine and Freshwater Research 21:175-191

Birkinshaw N, Kemp E, Clarke S (2013) The ecology of grass-wrack pondweed Potamogeton Compressus. Natural England Commissioned ReportsNumber 130

Boelee N, Temmink H, Janssen M, Buisman C, Wijffels R (2011) Nitrogen and phosphorus removal from municipal wastewater effluent using microalgal biofilms. Water Research 45(18):5925-5933

Boylan JD, Morris J (2003) Limited effects of barley straw on algae and zooplankton in a Midwestern pond. Lake and Reservoir Management 19:265-271

Brönmark C (1989) Interactions between epiphytes, macrophytes and freshwater snails: a review. Journal of Molluscan Studies 55:299-311

Brönmark C, Rundle SD, Erlandsson A (1991) Interactions between freshwater snails and tadpoles: competition and facilitation. Oecologia 87:8-18

Caffrey J, Monahan C (1999) Filamentous algal control using barley straw. Hydrobiologia 415:315-318

Calow P, Calow LJ (1975) Cellulase activity and niche separation in freshwater gastropods. Nature 255:478-480

Carpenter S, Caraco N, Correll D, Howarth R, Sharpley A, Smith V (1998) Nonpoint pollution of surface waters with phosphorus and nitrogen. Ecological Applications 8(3):559

Chambers PA, Prepas EE, Bothwell ML, Hamilton HR (1989) Roots versus shoots in nutrient uptake by aquatic Macrophytes in flowing waters. Candian Journal Of Fisheries And Aquatic Sciences 46:435-439

Cheney C, Hough RA (1983) Factors controlling photosynthetic productivity in a population of Cladophorafracta (Chlorophyta). Ecology 64:68-77

Chislock MF, Doster E, Zitomer RA, Wilson AE (2013) Eutrophication: causes, consequences, and controls in aquatic ecosystems. Nature Education Knowledge 4(4): 10

Colletti PJ, Blinn DW, Pickart A, Wagner VT (1987) Influence of different densities of the mayfly grazer Heptagenia Criddlei on lotic diatom communities. Journal of the North American Benthological Society 6:270-280

Dillon PJ, Rigler FH (1974) A test of simple nutrient budget model predicting the phosphorus concentration in Lake water. Journal of the Fisheries Research Board of Canada 31:1771-1778 
Everall NC, Lees DR (1996) The use of barley straw to control general and blue-green algal growth in a Derbyshire reservoir. Water Research 30:269-276

Feminella JW, Hawkins CH (1995) Interactions between stream herbivores and Periphyton; a quantitative analysis of past experiments. Journal of North American Benthological Society 14:465-509

Ferber LR, Levine SN, Lini A, Livingston GP (2004) Do cyanobacteria dominate in Eutrophic Lakes because they fix atmospheric nitrogen? Freshwater Bioogy. 49:690-708

Gao J-Q, Xiong Z-T, Zhang W-H, Deng X-W, Shang L-Y, Fu C-Y (2007) Removal efficiency of phosphorus in hypertrophic lake donghu water by common submerged macrophytes; resources and environment in the Yangtze Basin. School Of Resource And Environment, Wuhan University, Wuhan 430072, China

Geiger S, Henry E, Hayes P, Haggard K (2005) Barley straw - algae control literature analysis

Gibson MT, Welch IM, Barrett PRF, Ridge I (1990) Barley straw as an inhibitor of algal growth II: laboratory studies. Journal of Applied Phycology 2:241-248

Gregory SV (1983) Plant-herbivore interactions in stream systems. In: Barnes JR, Minshall GW (eds) Stream ecology: application and testing of general ecological theory. Plenum, New York, pp 159-189

Hosper SH (1989) Biomanipulation, new perspective for restoring Shallow Lakes in the Netherlands. Hydrobiologia Bulletin 23:5-10

Houman Rajabi Islami HR, Filizadeh Y (2011) Use of barley straw to control nuisance freshwater algae. American Water Works Association (Awwa) 103:5-12

Hutchinson GE (1975) A treatise on limnology, vol Iii. Limnological Botany. John Wiley \& Sons, New York

Jacoby JM (1987) Alterations in Periphyton characteristics due to grazing in a Cascade foothill stream. Freshwater Biology 18:495-508

Jeppesen E (1998) The ecology of Shallow Lakes - trophic interactions in the Pelagial. D.Sc. Dissertation. Ministry Of Environment And Energy, National Environmental Research Institute

Jeppesen E, Kristensen P, Jensen J, Sondergaard M, Mortensen E, Lauridsen T (1991) Recovery resilience following a reduction in external phosphorus loading of shallow eutrophic Danish lakes: duration, regulating factors and Methods for overcoming resilience. Istituto Italiano Di Idrobiologia 48:127-148

Lamberti GA, Moore JW (1984) Aquatic insects as primary consumers. In: Resh VH, Rosenberg DM (eds) The ecology of aquatic insects. Praeger, New York, pp 164-195

Lidén A (2016) Safe drinking water in a changing environment: membrane filtration in a Swedish context. Lund University, Water Resources Engineering

Maberly SC, King L, Gibson CE, May L, Jones RI, Jordan MMD aC (2003) Linking nutrient limitation and water chemistry in Upland Lakes to catchment characteristics. Hydrobiologia 506:83-91

Martin D, Ridge I (1999) The relative sensitivity of algae to decomposing barley straw. Journal of Applied Phycology 11:285-229

Meijer ML, Raat AJ, Doef RW (1989) Restoration by biomanipulation of Lake Bleiswijkse zoom the Netherlands first results. Hydrobiology Bulletin 23:49-58

Moss B (2001) The broads. The People's wetland. The new naturalist. Harper Collins Publishers, London

Nelson C, Bennett D, Cardinale B (2013) Consistency and sensitivity of stream periphyton community structural and functional responses to nutrient enrichment. Ecological Applications 23(1):159-173

Newman JR, Barrett PRF (1993) Control of Microcystis Aeruginosa by decomposing barley straw. Journal ofAquatic Plant Management 31:203-206

Ozimek T, Gulati RD, Van Donk E (1990) Can Macrophytes be useful in biomanipulation of lakes? The Lake Zwemlust example. Hydrobiologia 200/201:399-407
Phillips GL, Eminson D, Moss B (1978) A mechanism to account for macrophyte decline in progressively eutrophicated freshwaters. Aquatic Botany 4:103-126

Phillips G, Willby N, Moss B (2016) Submerged macrophyte decline in shallow lakes: what have we learnt in the last forty years? Aquatic Botany 135:37-45

Power ME, Stewart AJ, Matthews WJ (1988) Grazer control of algae in an Ozark Mountain stream: effects of short-term exclusion. Ecology 69:1894-1898

Pretty JN, Mason CF, Nedwell DB, Hine RE, Leaf S, Dils R (2003) Environmental costs of freshwater Eutrophication in England and Wales. Environmental Science \& Technology 37:201-208

Prygiel E, Charriau A, Descamps R, Prygiel J, Ouddane B, Billon G (2014) Efficiency evaluation of an Algistatic treatment based on barley straw in a hypertrophicpond. J Environ Eng Landsc Manag 22(1):1-13

R Core Team (2015) R: A language and environment for statistical computing. R Foundation for Statistical Computing, Vienna, Austria. https://www.R-project.org/. Accessed 28 Jan 2018

Ridge I, Pillinger JM (1996) Towards understanding the nature of algal inhibitors from barley straw. Hydrobiologia 340:301-305

Scheffer M (1998) Ecology of Shallow Lakes. Chapman And Hall, London, p 357

Scheffer M, Van Nes EH (2007) Shallow Lakes theory revisited: various alternative regimes driven by climate, nutrients, depth and Lake size. Hydrobiologia 584:455-466

Scheffer M, Hosper SH, Meijer ML, Moss B, Jeppesen E (1993) Alternative equilibria in Shallow Lakes. Trends in Ecology and Evolution 8:275-279

Schindler D (2006) Recent advances in the understanding and management of eutrophication. Limnology and Oceanography 51(1):356-363

Skoog G (1978) Influence of natural food items on growth and egg production in brackish water populations of Lymnaea Peregra and Theodoxus Uviatilis (Mollusca). Oikos 31:340-348

Smith CS, Barko JW (1990) Ecology of Eurasian watermilfoil. Journal of Aquatic Plant Management 28:55-64

Søndergaard M (2007) Nutrient dynamics in lakes - with emphasis on phosphorus, sediment and Lake restorations. Doctor's dissertation (Dsc). National Environmental Research Institute, University Of Aarhus, Denmark. 276 Pp.

Spence DHN (1982) The zonation of plants in Freshwater Lakes. In: Macfadyen A, Ford ED (eds) Advances in ecological research. Academic Press, London, pp 37-126

Steinman AD, Mcintire CD, Gregory SV, Lamberti GA, Ashkenas LR (1987a) Effects of herbivore type and density on taxonomic structure and physiognomy of algal assemblages in laboratory streams. Journal of the North American Benthological Society 6:175-188

Steinman AD, Mcintire CD, Lowry RR (1987b) Effects of herbivore type and density on chemical composition of algal assemblages in laboratory streams. Journal of the North American Benthological Society 6:189-197

Stevenson RJ, Bothwell ML, Lowe RL (1996) Freshwater benthic systems. Academic Press; Eds. Algal Ecology, San Diego

Timm RM, Moss B (1984) Prevention of growth of potentially dense phytoplankton populations by zooplankton grazing in the presence of Zooplanktivorus fish. In: a shallow wetland ecosystem. Limnology and Oceanography 29:472-486

Underwood GJC, Thomas JD, Baker JH (1992) An experimental investigation of interactions in snail macrophyte-epiphyte systems. Oecologia 91:587-595

Urrutia-Cordero P, Ekvall MK, Ratcovich J, Soares M, Wilken S, Zhang H, Hansson L-A (2017) Phytoplankton diversity loss along a gradient of future warming and brownification in freshwater mesocosms. Freshwater Biology 10:1111-13027 
Welch EB, Horner RR, Patmont CR (1989) Prediction of nuisance Periphytic biomass: a management approach. Water Research 23: 401-405

Welch IM, Barrett PRF, Gibson MT, Ridge I (1990) Barley straw as an inhibitor of algal growth in: studies in the Chesterfield Canal. Journal of Applied Phycology 2:231-239

Welch EB, Quinn JM, Hickey CW (1992) Periphyton biomass related to point-source nutrient enrichment in seven New Zealand streams. Water Research 26:669-675
Xin L, Hong-Ying H, Ke G, Ying-Xue S (2010) Effects of different nitrogen and phosphorus concentrations on the growth, nutrient uptake, and lipid accumulation of a freshwater microalga Scenedesmus Sp. Bioresource Technology 101(14):5494-5500

Publisher's Note Springer Nature remains neutral with regard to jurisdictional claims in published maps and institutional affiliations. 